\title{
A design framework for measuring transit oriented development
}

\author{
Y. J. Singh, M. H. P. Zuidgeest, J. Flacke \\ \& M. F. A. M. van Maarseveen \\ University of Twente, Faculty of Geo-Information Science and \\ Earth Observation, The Netherlands
}

\begin{abstract}
Transit Oriented Development (TOD) has been a promising concept to establish land use and transport integration, thereby creating more sustainable communities. Literature suggests that the benefits of TOD are manifold but also different for each stakeholder. A literature survey furthermore reveals that there is no standard definition nor a generally accepted aim for TOD, which is not very surprising because of the different perspectives of stakeholders in the process of achieving TOD. In addition it has been found that different methods and various sets of indicators to evaluate and measure TOD have been proposed. Examination of a number of case studies shows that these methods have hardly been operationalised. To guide decision making for new transit oriented development(s) it is essential to have a framework and a tool to quantitatively measure current levels of TOD at a location and in an area. The tool also needs to be flexible and able to support participatory planning processes. This paper provides a literature survey on the TOD concept and its operationalisations and it presents a design framework for a tool that enables quantitative measurement of TOD.

Keywords: transit oriented development, SMCA, SDSS, measuring TOD, TOD index.
\end{abstract}

\section{Introduction}

Transit Oriented Development (TOD) relates to spatial planning for development around transit stations that is oriented towards the transit system. TOD as a planning tool is expected to integrate the land use and transport systems, and 
thereby creates lively, sustainable, pedestrian and cycling friendly areas and neighbourhoods. The concept of transit oriented development has been worked upon by many researchers and practitioners since many years. TOD projects pursue various goals and build upon different definitions of TOD. Much work has been done to identify indicators for measurement and evaluation of TOD. Review of case studies brings out the need for quantitative measurement of existing TOD levels or TOD-ness of an area. To address this need, a design framework has been proposed to build a tool that quantitatively measures existing levels of TOD on a geo-spatial platform and represents the results in the form of 'TOD index'. The results can further be used in a spatial decision support system (SDSS) to plan for improving TOD levels in a case. From this point onwards, 'measuring TOD' shall mean 'measuring existing levels of TOD' and 'evaluating TOD' shall mean 'evaluating the outcomes of TOD plans'.

\section{What is TOD and what is its aim?}

Transit Oriented Development has been defined by various authors at different times and places. Peter Calthorpe [1], who is considered a pioneer of the TOD concept has defined TOD as “..... mixed use community within an average 2000 foot walking distance of a transit stop and core commercial area. TODs mix residential, retail, office, open space, and public uses in a walkable environment, making it convenient for residents and employees to travel by transit, bicycle, foot or car". According to him, walkable environment is the key aspect of TOD, as through TOD sprawl can be controlled and car trips are reduced by letting people walk to complete their tasks, including walk to and from transit stops (access and egress).

While Calthorpe's definition focuses more on the physical characteristics of the surrounding area of a transit stop, Schlossberg and Brown [2] define TOD as an "...integrated approach to transportation and land use planning". The main goal of TOD, they state, is to create more benefits than costs on both the regional and local scale.

Similarly, Boarnet and Crane [3] describe TOD as ".....the idea that land near rail transit stations should be developed or redeveloped in ways that encourage the best use of the transit system and that leverages the public investment in rail transit". They also define TOD as "...the practice of developing or intensifying residential land use near the stations". Since their work was specifically about residential areas near rail stations, their description of the concept is also narrowed down to the residential areas and rail transit.

Later, in 2002, Parker et al. [4] conducted a research on factors for success of TOD in California and defined TOD as “......moderate to higher density development, located within an easy walk of a major transit stop, generally with a mix of residential, employment and shopping opportunities designed for pedestrians without excluding the auto. TOD can be new construction or redevelopment of one or more buildings whose design and orientation facilitate transit use". 
Further, Reconnecting America, a national (US) non-profit organization working on TOD, has defined TOD as being "really about creating walkable, sustainable communities for people of all ages and incomes and providing more transportation and housing choices (including town-homes, apartments, livework spaces, and lofts)." (CTOD [5]).

Hale and Charles [6] provided a 'working definition' of TOD in their paper as "A vibrant, relatively dense and pedestrianized mixed-use development precinct, featuring quality public space and immediate access to high-frequency public transit".

In contrast to all of the above, Dittmar and Poticha [7] have given a performance based definition of TOD saying that "the term Transit Oriented Development should be reserved to refer to projects that achieve five main goals - location efficiency, rich mix of choices, value recapture, place making, resolution of tension between node and place." They also say that"....the main goal of TOD, (which) is not to create physical form but rather to create places that function differently than conventional development" and also "...to support functioning of a transit system".

It can be seen that TOD has various definitions and different people have different expectations of TOD. As the intended aim of TOD changes, the definition changes too. Hence, we do not have a singular definition of TOD. In essence, they can be called descriptions.

These descriptions of TOD do not say much about the transit system even though the design and quality of transit service has a major impact on success potential of the TOD and a TOD plan can fail if the transit is not good enough. Newman [8] opines that for a transit system to be successful, it must be able to compete with private transport in speed and capacity. As a rule of thumb, a good quality transit system must be a high frequency service along fixed lines and with fixed times that make it reliable and user friendly.

There has also been much discussion in the literature by Newman [8], Newman and Kenworthy [9], Hale and Charles [6] and Hoffman [10], about what kind of transit system can fulfil these expectations and which ones cannot. Usually, while planning for TOD around a station location, the service levels of the transit system are not assessed or evaluated. However - not to be overlooked - if the transit system is not inviting enough, no effort in TOD planning can increase the utilization of the transit system.

But, the absence of transit system requirements in TOD descriptions may not be without a reason. While transit-oriented developments can only be planned around an efficient and dependable transit system, the concept of TOD as such does not involve planning for or improvisation of the transit system. The concept of TOD is all about planning for developments that are transit oriented provided that that location is served by a dependable and efficient transit system.

The most important ingredient to success of TOD planning is 'land use transport/transit integration'. Unless, the development interacts with the transit system, the two systems - land use and transit, shall stand alone, independent like acquaintances but not friends. This is also called TAD, an evil brother of TOD, as categorized by G.B. Arrington (in Halbur [11]). TAD is 'Transit 
Adjacent Development', whereby the development around a transit station just sits there and has little or no orientation or interaction with the transit system. One can also say that the one thing that differentiates TOD and TAD is the 'land use- transport integration', which must be taken care of at the stage of planning TOD. The next section details out planning practice for TOD.

\section{Where is TOD planned and how?}

The Centre for Transit Oriented Development (CTOD [5]) and Reconnecting America (Zimbabwe and Anderson [12]) stress that TOD planning must be done at regional, urban and local levels. At the same time, since transit oriented development is about conducive development around the transit stops/stations, the scale of TOD planning at station level, is most crucial. In the TOD handbook of The City of Calgary [13], it is mentioned that "The distance that a person is willing to walk to take transit defines the primary area within which TOD should occur. This distance is equivalent to roughly a 5 minute walk, or 400 to 600 meters. At these radii around a station, there is potential for 125 to 250 acres of land for TOD".

However, for the entire transit system to benefit from TOD planning, it is important for station plans to stitch together in the larger picture at urban and regional level. A successful TOD plan requires thinking and planning beyond the individual station and understanding the role of each station and its neighbourhood in the regional network of a transit system. A regional TOD plan ensures that there is coordination between itself and other existing regional plans for growth, infrastructure etc. It also identifies common goals and coordination for different urban bodies.

At the local scale, i.e. station area and its neighbourhood level, it is important to understand the pulse of the community and the need to promote/ develop transit oriented activities. "The Transit-oriented Development Program takes planning from the conceptual to the actual by investing in development projects in key locations throughout the region" (CTOD [14]).

It has also been suggested by other authors that for a TOD to make substantial / meaningful difference in development patterns, it must consider the regional level and not exclusively the area within the quarter-mile of a local station/ stop. Newman [8] points out that while planning for densities and development mixes, the local government's plans must adhere to regional priorities. Local government is usually very closely tied in the local politics and there may be local groups who are opposed to redevelopment plans and density increases. While TOD should enable affordable housing near the stations, local communities may not prioritize this development as people often believe that high density can be socially dangerous and unhealthy. Thus, to ensure that regional priorities do not get diluted at local level, the TOD planning cannot be left to local politics.

Hence, it can be inferred that TOD planning cannot be restricted to local level as public transport covers large parts of the urban areas and area-wide planning is very important. At the same time, station level planning remains crucial since 
that is where the project implementation takes place. TOD planning is thus inherently spatial.

But how does one plan for TOD? TOD planning practice has mostly been done by way of increasing the densities. Aiming for high densities, by way of easing the zoning regulations, has been seen as the most common form of TOD planning, even though, it is important to understand that TOD proposals are not like stencils and have to be tailor-made. A transit oriented development is characterized not just by high densities, but also by a healthy mix of uses and pedestrian friendliness among others. Like other infrastructure projects, here too, it is important to measure the existing situation using quantitative methods, so as to be able to ascertain specific planning interventions that would be suitable.

TRB [15] concludes in its report on measuring TOD by stressing on the fact that public investments in infrastructure are too often made without understanding the existing situation and possible outcomes of their plans. One of the reasons that poor decisions are made over and over again is that "few planners and policy makers evaluate the failures or successes of similar projects before embarking on new ones". It further stresses that "Without measuring the outcomes of TODs, mistakes in investment strategies will continue to be repeated".

This clearly emphasizes that planning for TOD should also be preceded by more quantitative understanding of the existing situation which, in turn requires measuring existing levels of TOD. Quantitative evaluation of similar TOD projects elsewhere, can also give much needed lessons while planning, regarding what may support or limit success of the TOD plans. This brings us to the next section where different methods to measure TOD-ness and evaluate TOD, as have been proposed in literature, are explained.

\section{How is TOD measured and evaluated?}

In the previous section, it has been discussed that to plan for TOD, it is important to be able to measure TOD-ness as well as evaluate TOD at other locations. But, evaluation of success or failure can be gauged only when we know the ultimate goal of a step taken. Since TOD's aim changes for different stakeholders, the criteria for evaluation also differ. Renne [16] points out that evaluating the success of TOD depends upon the perspectives of different stakeholders.

A digest from TRB [15] discusses developing a strategy to 'measure the success of TOD'. This digest has built on a number of projects in America such as New Jersey transit village, Portland, California and other various case studies across America. It has identified and evaluated the indicators and identified 10 best indicators that can be used to monitor and evaluate TOD. It claims that except for studies focusing on transit ridership and land values near the stations little empirical studies have been carried out to evaluate TOD in a holistic manner. The ten most useful indicators suggested by this report are - transit ridership, density of development, quality of streetscape, quantity of mixed use development, pedestrian activity and safety, increase in property value and tax 
revenues, public perception, number of mode connections at the station/ stop and parking, in the ranking order.

Evans and Pratt [17] have pointed out that like the need to be able to evaluate success of TOD plans, there is also a need to express the existing TOD-ness of an area in terms of a 'TOD index'. The same work analysed the list of indicators proposed in TRB [15] and proposed its own lists of 'essential' and 'supportive' TOD indicators for TOD index calculation. These lists of indicators include the most 'quantifiable' aspects of TOD and were developed separately since it was believed that "outcome" indicators proposed in TRB [15] would not be suitable for use in the index calculation.

Belzer and Autler [18] argue that there is no standard benchmark for success of TOD since there is no universally accepted premise about what TOD should accomplish. They also believe that the varied definitions of TOD, available in literature, concentrate more on the physical form or design of TOD rather than the functional outcomes it should achieve. Hence, they propose a set of six performance criteria that can be used to evaluate project function and outcomes at station level. Using these, they believe, the real potential of TOD can be gauged. These criteria are - location efficiency, value recapture, liveability, financial return, choice of lifestyle and efficient land use patters at regional level (lesser sprawls). It may be noted that the above criteria are very familiar to the performance measures mentioned in the definition of Dittmar and Poticha [7], mentioned earlier. The authors have also suggested the ways of measuring these criteria using measurable outcomes of each of the above. It may however, be noted that these criteria are highly data intensive, collection of which can be a daunting task and not even possible at all times.

At the urban level, a TOD can be evaluated for success by measuring the increase in tax revenues, increase in transit ridership, increased land values and such. It is however, highly difficult to measure the regional level impact of the TOD. Nelson, Niles and Hibshoosh (TRB [15]) identified and listed 16 factors that can determine the success of TOD at regional as well as local scale as 'Factors Determining the Success of TOD'. At the same time, they have also asserted that the regional level impact of TOD is only a 'vision in the mind' of planners and cannot be quantified.

So far, this section has discussed availability of indicators that can be used to evaluate the success of TOD and measure TOD-ness at station location, urban and regional levels. As for the methods to measure and evaluate TOD, two approaches have been found as recommend by Renne [16]. These are regional performance approach (RPA) and community performance approach (CPA). These methods are meant to evaluate the success or failure of TOD plans. The RPA includes comparison between two or more TODs within a region, TOD and a non-TOD within a region, or TODs and regional averages of a region.

Under the CPA, a monitoring system specific to the community can be created to track TOD indicators towards achieving the local goals. Renne [19] has however also said that while it is almost impossible to find two developments that exhibit similar characteristics for comparison purposes, it is possible to collect the baseline data for a location, before the TOD is initiated 
and comparing that data with the data collected post-implementation, for the same location. This can help in evaluation of a success of a particular TOD project/ precinct. This method was used for Perth area, Australia in 2007. The study collected data through secondary surveys and household surveys for the 'existing' conditions around transit stations i.e. use of services, transit and commute patterns of people. After the implementation of TOD measures, data will be collected again from similar sources and compared with baseline data to see and measure the differences in the ground conditions due to TOD measures.

It may be noted here that both these methods, RPA and CPA, are methods of evaluation only, depending largely on the comparison of two or more locations. They are not meant to be used for measuring TOD-ness.

It can be concluded from literature review that while two methods namely RPA and CPA, have been proposed to evaluate the success of TOD plans, there are no proposed methods to measure TOD-ness. However, the indicators have been proposed both for evaluation and measurement purposes. The ensuing subsection will explain how theory has translated to practice. The literature is replete with case studies on TOD and quite a many have been read through to understand how TOD has been evaluated or measured in practice in those case studies.

\section{Existing case studies}

There are various case studies available in the literature on TOD each having a different focus and almost all deal only with evaluation of TOD and not the measurement of TOD-ness. Some case studies present an example of planned TOD at urban, regional or station level, some cases represent the successful role of private sector in TOD implementation and yet some cases evaluate TOD on TOD principles. More than a dozen case studies have been found (Curtis et al. [20], Cervero [21], Cascetta et al. [22], Cascetta and Pagliara [23], Cervero and Murakami [24], Hoffman [10]) from U.S., Australia, Italy, Brazil, Hong Kong and others.

After a careful evaluation of those case studies, it has been found that all of them are mainly qualitative descriptions, discussing one or more 'success/ failure factors' at that location. Notably, the case study description begins with a 'presumption' or a 'premise' about what makes that case study an example of successful or unsuccessful TOD. There is no quantitative analysis to show how this decision (i.e. if TOD plans were successful or not) was reached. It is only a discussion about what made it a good or a bad TOD example.

The work by Schlossberg and Brown [2] assesses 11 TOD sites in Portland, Oregon, using walkability indicator in GIS. It is an example of quantitatively measuring TOD-ness, albeit using only one indicator. This work is also unique as far as use of such spatial platforms for evaluation or measurement of TODness in concerned. There is also no available work where comprehensive TOD evaluation or measurement has been done at multiple scales - station, corridor and area-wide scales, together. Spatial representation and analysis has been found to be largely absent, even though it goes a long way in making the current 
situation more comprehendible to important stakeholders, such as private sector and the community, to visually see the existing situation on the map and plan for the future accordingly. The next sub section further elaborates the importance of a spatial platform in measuring TOD-ness and evaluating TOD.

\section{Spatial analytical platform and TOD}

Schlossberg and Brown [2] point out that it is the "fine grained, spatially explicit types of analyses that have been lacking in TOD" efforts. It is also mentioned by them that "visualizing urban form is also an important component to understanding walkability, especially for public understanding and participation in the planning process".

Same has also been stressed upon by Cervero and Bosselmann [25] in their work on visual simulation of possible TOD scenarios. Their work assesses the market potential of transit villages using visual simulation techniques, believing that "visual simulations provide a richer context for probing the market potential for transit-oriented development than do traditional market research approaches because visual simulations convey a wider array of environmental choices".

There are more reasons why TOD planning requires a spatial analytical platform. Since TOD is all about land use and transport planning, utilizing spatial analysis using maps and plans is inevitable. The definitions also suggest that the catchment areas of various transit systems in TOD should be within a radius of $250 \mathrm{~m}$ or $500 \mathrm{~m}$ from the transit station/ stop. Measuring TOD-ness also requires spatially explicit types of analyses using indicators that are also spatial in nature, while those indicators that are not explicitly spatial can at least be spatially visualised on a GIS platform.

Furthermore, as TOD measurement and evaluation should be done using multiple indicators, a multi-criteria assessment or alike is inevitable. Add to that the fact that TOD is planned at 3 different scales - station level, corridor level and area-wide; we need a multi-scalar method. Hence, multi-scalar, multi-criteria spatial assessment tools such as Spatial Multi-Criteria Analysis (SMCA) which is possible only over GIS should be considered. SMCA has for example been used in past by Keshkamat et al. [26] and Beukes et al. [27] in selection of the most appropriate road alignment and in multi-modal road planning, respectively. It is expected that with the aid of SMCA, TOD-ness can be quantitatively measured and represented as a TOD index for various locations in an area. In a Spatial Decision Support System (SDSS), various stakeholders can be invited to participate, understand what can be inferred from the TOD indices and propose specific TOD planning interventions for various locations in an area. Stakeholder participation in a transparent environment like that of SDSS will ensure practical and socially acceptable proposals.

Involvement of different stakeholders is also very important because the concept of TOD is open to different interpretations and definitions (as mentioned in earlier sections) and we must seek stakeholder participation in a spatial environment such as SDSS which is flexible enough to incorporate diverse views and allows for effective group discussions. 
To sum up, a multi-scalar and multi-criteria assessment can be done on a spatial platform. The results of this assessment can be used further in a flexible SDSS environment allowing incorporation of multi-stakeholder viewpoints.

\section{A design framework for measuring TOD}

As evident from the extensive review of literature, evaluation and measurement of TOD at a location has been discussed widely by various authors, but seldom translated into practice. Plus, the approaches and methods as proposed by Renne [16] are meant only for evaluation of TOD. Regarding measurement of TOD levels, no methods have been proposed so far. Evans and Pratt [17] note that there is a need to build a 'TOD Index' that can be used to quantitatively express the TOD-ness of a location and have proposed indicators too, that can be used for such calculation. But, they have stopped short of developing an index indicating scope for further research in development of the same.

The aim of our work is to be able to quantitatively measure TOD-ness and the results must be followed up by identifying specific interventions that will be needed to improve the TOD-ness. Since it is believed that various people hold stakes in TOD, it is imperative to involve the concerned stakeholders such as planners, transit agencies, community and private developers, in this discussion. Stakeholder participation is intended to take place twice in the process. Firstly, while assigning the weights to each indicator (to be used for TOD index calculation) and secondly, to discuss the TOD indices and decide on way forward. It is expected that different alternatives for different weights can be created and each alternative will have a separate TOD-index map. While the TOD index will be calculated using a spatial multi-scalar, multi-criteria assessment tool, the results will be used in a SDSS environment where multiple stakeholders can share their views and suggest interventions to improve TODness of each location.

In the same SDSS environment, locations with high TOD index but no transit connections can be brought to the notice of planners so that they can consider planning for extending their transit systems. Other stakeholders also stand to gain from this knowledge. As an example, private developers can plan and locate their developments near the planned extensions of transit system to benefit from the accessibility and connectivity that transit provides.

In figure 1, the design of the framework, discussed so far, has been shown for better understanding.

\section{Conclusions}

An extensive literature review reveals some well-known facts that TOD has different aims and definitions implying that TOD is open to interpretations by various stakeholders. It is also very clear that TOD is planned over multiple scales - station area level, transit corridor level and urban- regional level. At the same time, the review also reveals the lesser known facts that measurement of TOD-ness lacks quantitative approach. Case studies are also mainly examples of 
evaluation of TOD, albeit through methods of comparison or qualitative analysis and discussion. Even though there are indicators to quantitatively evaluate TOD and measure TOD-ness, they have not been used in practice. Since measuring TOD-ness is important for TOD planning and it has not been attempted before, there is a need to be able to quantitatively measure the TOD-ness of an area. It is our belief that GIS platform is vital for this since it allows multi-scalar and multi-criteria spatial assessment. A GIS platform also allows for collaborative inputs from multiple stakeholders to decide the way forward.

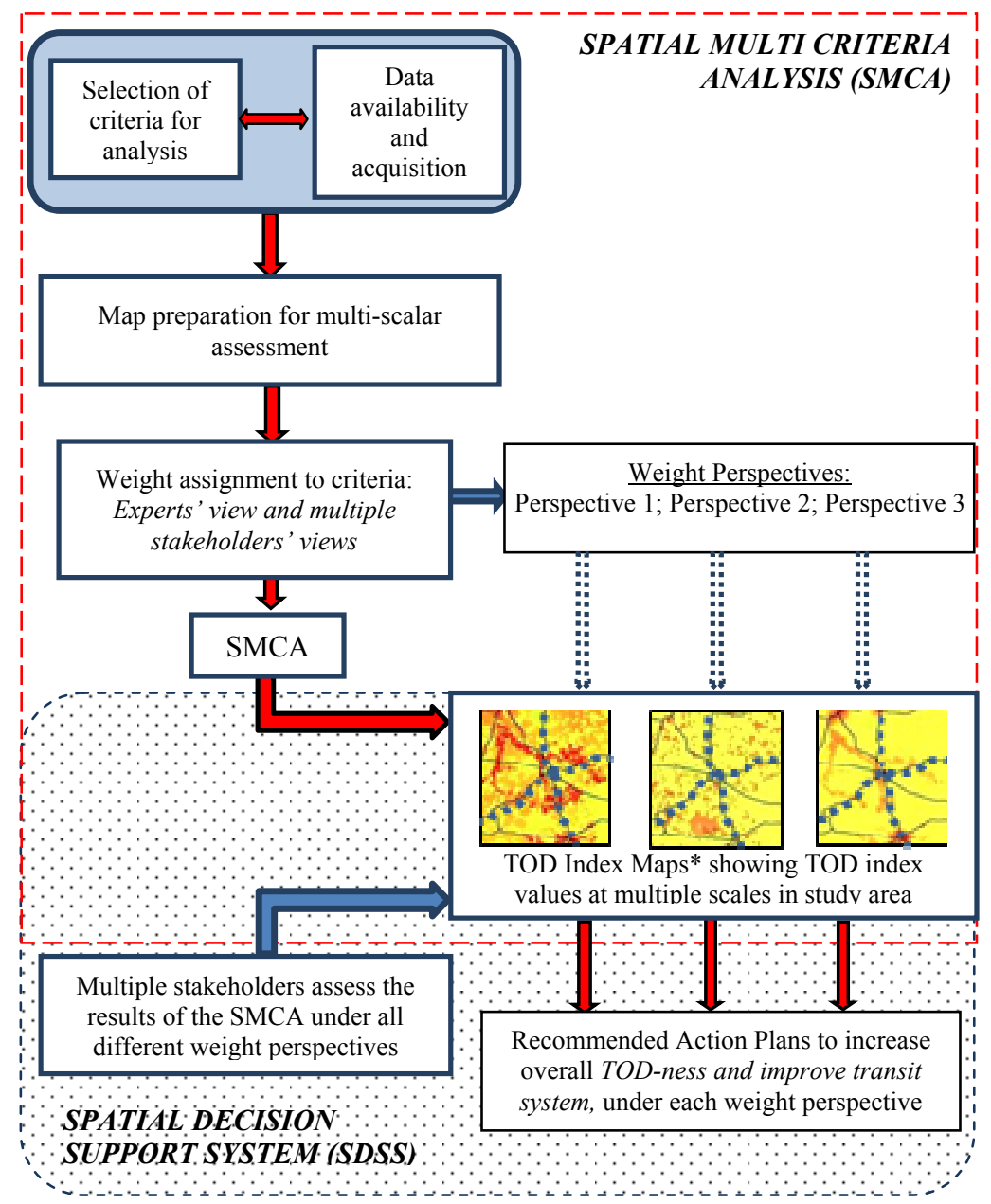

Figure 1: The design framework (*maps only for representation purposes).

This paper, hence, proposes a design framework to build a tool over a spatial platform of GIS, wherein multiple criteria analysis can help us quantitatively measure TOD-ness at multiple scales i.e. station area level, transit corridor level 
and area-wide level. The results shall then become an input to a SDSS environment, where multiple stakeholders can assess the results and thereafter propose planning actions and interventions to improve the TOD-ness of the study area.

\section{References}

[1] Calthorpe, P., The Next Americam Metropolis - Ecology, Community and the American Dream, Princeton Architectural Press: Canada. 1993.

[2] Schlossberg, M. and Brown, N., Comparing transit-oriented development sites by walkability indicators. Transit Planning and Development, Management and Performance, Marketing and Fare Policy, and Capacity and Quality of Service, (1887): p. 34-42, 2004.

[3] Boarnet, M. and Crane, R., L.A. story - A reality check for transit-based housing. Journal of the American Planning Association, 63(2): p. 189-204, 1997.

[4] Parker, T., McKeever, M., Arrington, G., and Smith-Heimer, J., Statewide Transit-Oriented Development Study: Factors for Success in California, 2002.

[5] CTOD, Why Transit - Oriented Development and Why Now?, Reconnecting America: U.S,

[6] Hale, C. and Charles, P., Making the most of transit oriented development opportunities, in 29th Australasian Transport Research Forum Manager, A.C., Editor 2006, The Australasian Transport Research Forum: Gold Coast, Queensland.

[7] Dittmar, H. and Poticha, S., Defining Transit-Oriented development: The New Reginal Building Block, in The New Transit Town - Best Practices in Transit Oriented Development, Dittmar, H., Ohland, Gloria., Editor Island Press, p. 19-39, 2004.

[8] Newman, P., Planning for Transit Oriented Development: Strategic Principles, in Transit Oriented Development: Making it Happen, Curtis, C., Renne, J.L., and Bertolini, L., Editors., Ashgate e-Book, p. 13-22, 2009.

[9] Newman, P. and Kenworthy, J., Greening Urban Transportation, in State of the world 2007 : our urban future (digital edition), Starke, L., Editor W.W. Norton \& Company: New York etc., p. 66-89, 2007.

[10] Hoffman, Transit: Can it sustain TOD?, The Mission Group, 2006.

[11] Halbur, T., TOD's Evil Twin: Transit-Adjacent Development. Available from: http:/www.masstransitmag.com/article/10221228/tods-evil-twintransit-adjacent-development.

[12] Zimbabwe, S. and Anderson, A., TOD 204 Planning for TOD at Regional Scale: The Big Picture, The Center for Transit-Oriented Development, 2011.

[13] The City of Calgary, Transit- Oriented Development : Best Practices Handbook, The City of Calgary, Jan 2004

[14] CTOD, Transit-Oriented Development Strategic Plan / Metro TOD Program, Metro TOD Program of Portland, Oregon, 2011. 
[15] TRB, Transit Oriented Development: Developing a Strategy to Measure Success, Transport Research Board, 2009.

[16] Renne, J.L., Measuring the Success of Transit Oriented Development, in Transit Oriented Development: Making it Happen, Curtis, C., Renne, J.L., and Bertolini, L., Editors., Ashgate e-Book, p. 241-257, 2009.

[17] Evans, J.E. and Pratt, R.H., Transit Oriented Development, Transport Research Board: U.S.A, 2007.

[18] Belzer, D. and Autler, G., Transit Oriented Development: Moving from Rhetoric to Reality, The Brookings Institution Center on Urban and Metropolitan Policy and The Great American Station Foundation, 2002.

[19] Renne, J.L., Measuring the Performance of Transit Oriented Development in Western Australia, Planning and Transport Research Centre and Institute for Sustainability and Technology Policy, Murdoch University, 2007.

[20] Curtis, C., Renne, J.L., and Bertolini, L., Transit oriented development: making it happen, Ashgate e-Book. 2009.

[21] Cervero, R., Transit-oriented development in the United States: experiences, challenges, and prospects, Transportation Research Board. 2004.

[22] Cascetta, E., Pagliara, F., and Coppola, P. The regional metro system project of Campania: Design methodology and impacts evaluation. in Third international conference on funding transportation infrastructure and tenth "Journeè transport", Parigi, p. 2008.

[23] Cascetta, E. and Pagliara, F., Integrated railways-based policies: The Regional Metro System (RMS) project of Naples and Campania. Transport Policy, 15(2), 2008.

[24] Cervero, R. and Murakami, J., Rail and Property Development in Hong Kong: Experiences and Extensions. Urban Studies, 46(10): p. 2019-2043, 2009.

[25] Cervero, R. and Bosselmann, P., Transit villages: Assessing the market potential through visual simulation. Journal of Architectural and Planning Research, 15(3): p. 181-196, 1998.

[26] Keshkamat, S.S., Looijen, L.M., and Zuidgeest, M.H.P., The formulation and evaluation of transport route planning alternatives: A spatial decision support system for the Via Baltica project, Poland. Journal of Transport Geography, 17(1): p. 54- 64, 2009.

[27] Beukes, E.A., Vandershurren, M.J.W.A., and Zuidgeest, M.H.P., Context sensitive multimodal road planning: a case study in Cape Town, South Africa. Journal of Transport Geography, 19: p. 452-460, 2011. 